
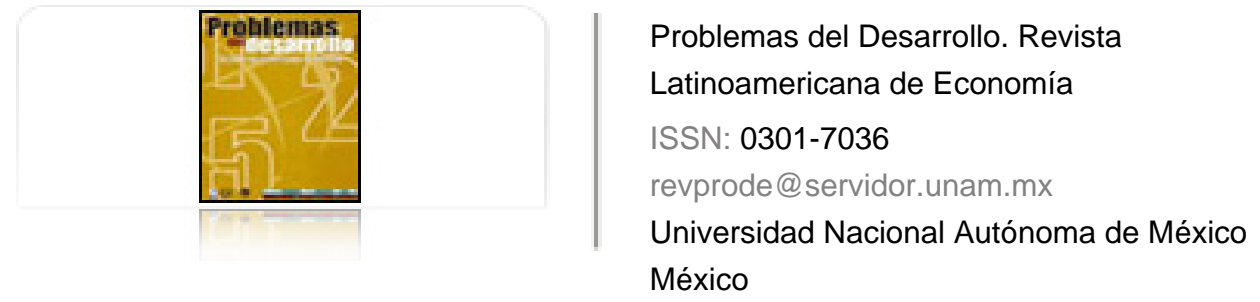

Crespilho Lourenço, Fabiano

EL SILENCIO ACADÉMICO SOBRE EL BANCO DEL SUR

Problemas del Desarrollo. Revista Latinoamericana de Economía, vol. 41, núm. 160, enero-marzo, 2010, pp. $135-155$

Universidad Nacional Autónoma de México

Distrito Federal, México

Disponible en: http://www.redalyc.org/articulo.oa?id=11820132007

- Cómo citar el artículo

- Número completo

- Más información del artículo

Página de la revista en redalyc.org

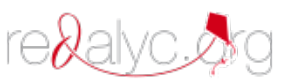

Sistema de Información Científica

Red de Revistas Científicas de América Latina, el Caribe, España y Portugal Proyecto académico sin fines de lucro, desarrollado bajo la iniciativa de acceso abierto 


\title{
EL SILENCIO ACADÉMICO SOBRE EL BANCO DEL SUR'
}

\author{
Fabiano Crespilho Lourenço*
}

Fecha de recepción: 1 de octubre de 2009. Fecha de aceptación: 20 de enero de 2010.

\section{Resumen}

El impulso inicial al Banco del Sur se relacionó con las ideas de la Alternativa Bolivariana para los Pueblos de Nuestra América y con una crítica contra el sistema capitalista. Pero desde 2006, el discurso de los diferentes actores en torno del proyecto del Banco del Sur se apaciguó hasta llegar a transformarse en propuestas conservadoras dirigidas a crear un mecanismo para proteger a la élite regional de la presente crisis económica mundial. El propósito de este artículo es señalar las perspectivas académicas en el debate que acompaña la trayectoria de construcción del Banco del Sur hasta julio de 2009, para así motivar una crítica capaz de revertir la actual alineación del proyecto con los patrones de reproducción de los mecanismos de expansión del sistema financiero internacional en el ámbito regional, de forma que se contribuya a romper con el modelo de financiamiento del desarrollo representado por las instituciones financieras multilaterales existentes.

Palabras clave: Banco del Sur, sistema capitalista, crisis económica, sistema financiero internacional.

1 Una primera versión del presente artículo es parte del estudio realizado en el capítulo 4 de la tesis de maestría El proyecto del Banco del Sur (Crespilho, 2009).

* El autor es maestro por la Facultad de Economía de la UNAM. Agradece las valiosas críticas y sugerencias de María Eugenia Correa Vázquez y Sergio Cabrera Morales. 


\section{Abstract}

The initial stimulus to the Banco del Sur was related to the ideas of the Bolivarian Alternative for the Peoples of Our America and to a critique of the capitalist system. But since 2006, the discourse of various actors on the Banco del Sur project has been modified and has ended up being transformed into conservative proposals aimed at creating a mechanism to protect the regional elite from the present world economic crisis. The proposal of this article is to outline the academic perspectives in the debate accompanying the trajectory of construction for the Banco del Sur to July, 2009, in order to promote a critique capable of reversing the present alignment of the project with the patterns of reproduction of the international financial system's expansion mechanisms in the regional orbit that will help to bring about a break with the model of development financing represented by the existing multilateral financial institutions. Key words: Banco del Sur, capitalist system, economic crisis, international financial system.

\section{Résumé}

L'impulsion donnée initialement à la Banque du Sud était liée aux idées de l'Alternative bolivarienne pour les Peuples de notre Amérique et à une critique du système capitaliste. Mais depuis 2006, le discours des différents acteurs en place à propos du projet de la Banque du Sud s'est apaisé au point de se convertir en propositions conservatrices destinées à créer un mécanisme pour protéger l'élite régionale face à l'actuelle crise mondiale. Le but de cet article est de mettre en évidence les perspectives académiques en jeu dans le débat qui a déterminé la trajectoire suivie pour la construction de la Banque du Sud jusqu'au mois de juillet 2009, afin de sustenter une critique capable de renverser l'actuel alignement du projet sur les schémas de reproduction des mécanismes d'expansion du système financier international dans la région, et contribuer ainsi à rompre avec le modèle de financement du développement que représentent les institutions multilatérales existantes.

Mots clés: Banque du Sud, système capitaliste, crise économique, système financier international.

\section{Resumo}

O impulso inicial ao Banco do Sul relacionou-se com as ideias da Alternativa Bolivariana para os Povos da Nossa América e com uma crítica contra o sistema capitalista. No entanto, desde 2006 o discurso dos diferentes atores em torno do projeto do Banco do Sul se apaziguou até chegar a se transformar em propostas conservadoras dirigidas a criar um mecanismo para proteger a elite regional da presente crise econômica mundial. O propósito deste artigo é assinalar as perspectivas acadêmicas no debate que acompanha a trajetória de construção do Banco do Sul até julho de 2009, para motivar assim uma crítica capaz de reverter a atual alienação do projeto com os padrões de reprodução dos mecanismos de expansão do sistema financeiro internacional no âmbito regional, de forma que se contribua para romper com o modelo de financiamento do desenvolvimento representado pelas instituições financeiras multilaterais existentes. Palavras-chave: Banco do Sul, sistema capitalista, crise econômica, sistema financeiro internacional.

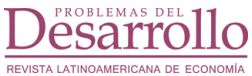

Vol. 41, núm. 160, enero-marzo / 2010 


\section{Introducción}

1 impulso inicial proporcionado por el gobierno venezolano al Banco del Sur
estuvo relacionado con las ideas de la Alternativa Bolivariana para los Pueblos
de Nuestra América y con una marcada crítica contra el sistema capitalista y, en especial, contra el neoliberalismo. Sin embargo, en la práctica, desde 2006 el discurso de los diferentes actores respecto del Banco del Sur se fue apaciguando hasta transformarse en nuevas propuestas más conservadoras. Su organización y operación están siendo promocionadas y analizadas en sus detalles económicos por los ministerios de Economía y Finanzas de los países sudamericanos, por organizaciones no gubernamentales y por académicos y analistas económicos como un mecanismo útil

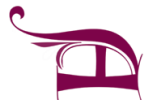
para salir o protegerse de la presente crisis mundial ${ }^{2}$. El propósito de este artículo es identificar las perspectivas académicas en el debate que acompaña la trayectoria de construcción del proyecto del Banco del Sur, como una condición necesaria para entender tanto su gestación como su futuro, además de apoyar el estudio crítico de este importante proyecto, como el realizado en el artículo Banco del Sur y medio ambiente (Crespilho, 2010).

Además, el trabajo ayuda a contestar la pregunta de ¿en qué medida el proyecto del Banco del Sur se inserta en la construcción de mecanismos en la escala regional que contrarresten el actual patrón de reproducción de la esfera financiera del sistema capitalista?

Lo anterior permitirá identificar los elementos del debate que puedan auxiliar en la creación de un Banco del Sur que sea incompatible con la reproducción de los mecanismos de expansión del sistema financiero internacional en el ámbito regional, de manera que se rompa con el modelo de financiamiento del desarrollo representado por las instituciones financieras multilaterales existentes. Tal esfuerzo tiene el interés de fomentar una investigación del Banco del Sur menos tendenciosa que la aceptación preestablecida de que el proyecto sea necesariamente una alternativa a la condición del subdesarrollo sudamericano.

En este sentido, el Banco del Sur puede contribuir a atenuar el crecimiento de la influencia de la esfera financiera privada en el espacio regional sudamericano, así como a eliminar en este ámbito algunos elementos que atan las economías de la región a la

2 Cfr., por ejemplo, Valenzuela (2009).

Vol. 41, núm. 160, enero-marzo / 2010

Dessarroullo 
condición de subdesarrollo. Empero, para que eso sea posible en la dimensión material y dentro del capitalismo, esta nueva institucionalidad financiera regional debe ser capaz de crear mecanismos para propiciar una inversión productiva y una acumulación de capital que sean alternativos. Si la búsqueda se orienta hacia el desarrollo capitalista endógeno, el Banco del Sur debe tener el poder de crear una estructura crediticia de fomento a la inversión productiva y que posibilite el aislamiento de las decisiones económicas de la región de los ánimos de los mercados financieros internacionales. En especial debe ser un banco público alternativo al Banco Interamericano de Desarrollo (BID) y al Banco Mundial (BM) (Toussaint, 2006; Toussaint, 2008).

\section{Discurso fundador}

El discurso inicial de la propuesta del Banco del Sur plantea, tal y como se lee textualmente en el Acta Fundacional del Banco del Sur de 2007,

crear un banco de desarrollo con el carácter de persona jurídica de derecho público internacional que se denominará Banco del Sur, el que tendrá por objeto financiar el desarrollo económico y social de los países de la Unión de Naciones Sudamericanas (Unasur) miembros del Banco, en forma equilibrada y estable haciendo uso del ahorro intra y extrarregional; fortalecer la integración; reducir las asimetrías y promover la equitativa distribución de las inversiones dentro de los países miembros del Banco. (Acta Fundacional del Banco del Sur, 2007: 2.)

Primero, para cumplir con los objetivos de "financiar el desarrollo económico y social" -o sea, objetivos de un banco de desarrollo- se propone que su capital accionario sea constituido inicialmente por parte de las reservas de divisas fuertes ${ }^{3}$ de los países miembro, y que el fondeo sea realizado por bonos u otras operaciones pasivas para establecer pasivos en diversas monedas, atrayendo, además, parte del "ahorro privado intrarregional".

Luego, el financiamiento del desarrollo que se divide, en la práctica, entre el financiamiento: 1) de la inversión productiva y la industrialización; 2) de la pequeña, mediana y gran unidad productiva de bienes transables intra y extrarregionalmente (commodities); 3) de la reducción de las asimetrías regionales; 4) de proyectos sociales; y, primordialmente, 5) de la construcción de la infraestructura de integración ener-

3 En las propuestas más recientes, y en el borrador de junio de 2008 del convenio constitutivo, los países miembro deberán aportar su cuota de capital accionario en dólares estadounidenses (90\% mínimo) y moneda nacional (10\% máximo). 
gética y comercial de gran escala, demandada por las actuales políticas de desarrollo de los gobiernos de la región.

Otro objetivo presente en las versiones iniciales del proyecto o en aquéllas defendidas por los actores más críticos es la coordinación de políticas intrarregionales en las áreas macroeconómica y monetaria. O sea, más allá de un banco de desarrollo, se proponía el Banco del Sur como un importante e integrador pilar financiero de la Unasur, al lado de los proyectos de una unión monetaria y del fondo monetario (fondo de estabilización monetario) regionales ${ }^{4}$.

Aunque la propuesta ahora triunfante se limita a un banco de desarrollo público altamente compatible con los mercados privados de capitales, se espera que la captación de fondos por medio de emisión de bonos en los mercados financieros nacionales e internacionales también atraiga los ahorros privados regionales en la forma de inversiones de mediano y largo plazos de los agentes domésticos, concentradores del excedente capitalista regional. Se propone, por algunos, que la emisión de estos bonos se realice también en monedas nacionales, buscando elevar la conexión entre la ganancia financiera, el ahorro y la ganancia productiva capitalista regionales en los mercados financieros secundarios de estos bonos; en contraposición a la condición de "casino financiero" de esos mercados, de cierto modo dicha propuesta favorecería su control y su regulación. Se espera que el crecimiento bien distribuido del aprovisionamiento de créditos en monedas nacionales por todos los países miembro, incluyendo las grandes y pequeñas economías, permita la diversificación de la cartera de débitos del Banco del Sur en términos de monedas, con la finalidad de reducir el riesgo cambiario de las emisiones de títulos de la institución. Además, si el volumen de las operaciones del Banco fuera suficientemente grande, esta diversificación también apoyaría la estabilidad cambiaria del segmento de los mercados financieros en que actúa. Es decir que por la intervención del Banco del Sur también se espera que cuanto mayor sea la interpenetración de activos denominados en monedas nacionales sudamericanas en los mercados financieros domésticos, menor será la variación y posibilidades de desalineaciones de los tipos de cambio intrarregionales y menor la diferencia entre las tasas de interés entre los activos denominados en estas monedas. Con ello, sería más factible el diseño de una coordinación de políticas monetaria y macroeconómica intrarregionales.

Además, es posible que el Banco del Sur produzca significativa información financiera regional basada en estadísticas, documentos técnicos, análisis, críticas, re-

\footnotetext{
4 Cfr. Declaración de Quito (2007).
} 
señas de proyectos, etc., que apoye el crecimiento de una nueva y endógena ciencia económica con intereses regionales. Dicha información sería necesaria especialmente si el sistema financiero regional propuesto, en el marco de la Unión de Naciones Suramericanas, pretendiera tener una actuación macroeconómica y sobre los sistemas financieros regionales, más allá de la complementariedad de los recursos financieros para el financiamiento de la inversión.

El proceso de disminución de las asimetrías de los niveles de desarrollo económico de las naciones sudamericanas se realizaría mediante políticas de redistribución del capital para inversión dentro de la región. Objetivo justificado por el deseo de crecimiento de la producción, de la tasa de ganancia capitalista y de los mercados consumidores regionales, así como por el reconocimiento de que la integración de los procesos productivos en el ámbito intrarregional puede elevar la tasa de ganancia en el ámbito regional sin deterioro del nivel de ganancias en las naciones más desarrolladas de la región.

Para atender a todas las propuestas anteriores, es importante destacar que el Banco del Sur tiene el desafío de ir más allá de la reunión del "ahorro" regional y de la complementariedad del volumen de recursos disponibles para inversión productiva regional. Su gobierno debería actuar coherentemente con la orientación de políticas públicas puestas específicamente para resolver los problemas estructurales del subdesarrollo en el contexto económico de Sudamérica. De hecho, el cambio estructural es el objetivo principal detrás de la crítica en contra de las ideas neoliberales presentes en el debate por la integración financiera que se analiza a continuación.

No obstante, no se puede ignorar que este "desarrollo" material implica la elevación simultánea de la exploración de materias primas, de la maximización del uso de las fuentes energéticas y de la mayor producción de bienes en la región, o sea, la mayor explotación de la base material regional.

\section{El debate académico}

Una de las bases académicas del proyecto del Banco del Sur se apoya en la crítica al proyecto neoliberal en Sudamérica; crítica que enfatiza la necesidad de cambio estructural hacia un nuevo sistema o paradigma financiero regional. Proponiendo un sistema que consienta la mitigación de la dependencia hacia los mercados financieros internacionales y que ayude a deshacer parte de los nudos que atan a las naciones sudamericanas en la condición económica, política, cultural y social del subdesarrollo.

A pesar de eso, una parte importante de la producción y análisis sobre el tema no comparte esta visión. Mucha de la discusión en apoyo al Banco del Sur propone la 
complementariedad del volumen de recursos para la inversión regional en la forma ya realizada por los mercados financieros privados, por el BM, el BID y las instituciones subregionales existentes, sin cambios estructurales, de manera que tiende a fortalecer el patrón sistémico actual.

$\mathrm{Al}$ proponer la mera complementariedad de recursos, se acepta el argumento neoliberal de la existencia de una estructural escasez regional de recursos (ahorro) para las necesidades financieras del desarrollo, que se resuelve por medio de la transferencia de capitales excedentes -básicamente en las monedas de los EEUU, Europa y Japón- para las inversiones productivas del Sur.

En lugar de combatir este patrón de organización y comportamiento sistémico comprendido como ideología neoliberal ${ }^{5}$, el Banco del Sur pudiera ser empleado para alimentarlo y ayudar a reproducirlo. La consecuencia global de lo anterior es una mayor producción regional, financiada por los recursos del Banco del Sur, sin una mitigación de los mecanismos de transferencias de los excedentes hacia el Norte geopolítico, lo que podría implicar una transferencia neta aún mayor que la actual.

Aunque en la práctica las dos posiciones (cambio estructural frente a complementariedad de recursos) no existen de forma aislada y, más bien, se mezclan en la producción académica, identificar esta dicotomía ideal parece ser importante. Así que examinemos por un momento estas dos ideas.

\section{Banco del Sur: complementariedad de recursos}

En primer lugar se analiza la perspectiva que privilegia la funcionalidad del Banco del Sur para atender la complementariedad de los recursos y ahorro regionales.

A propósito de esta perspectiva, el objetivo del Banco del Sur sería elevar la capacidad de financiamiento del desarrollo con énfasis en la extracción, transformación,

5 No confundir con el discurso antiimperialista y nacionalista en que el empleo del término neoliberal representa un conjunto más amplio de problemas políticos (y reivindicaciones) que en el sentido empleado en el texto. En la perspectiva propuesta, medidas neoliberales refiere al conjunto de ideas y las consecuentes políticas adoptadas por los gobiernos (durante las décadas de 1980-1990 en Latinoamérica) que liberalizaron las cuentas de capitales domésticos y abrieron sus mercados financieros para el libre flujo de capitales estadounidenses, europeos y japoneses, sin importar su origen, destino ni tiempo de permanencia en los mercados nacionales. Tal ideología plantea que una vez liberalizado el sistema financiero, el desarrollo deriva automáticamente del crecimiento y de la cualidad de las inversiones, de modo que las economías nacionales sólo tienen que garantizar la estabilidad del sistema financiero y de las variables macroeconómicas, en general, para que los flujos de capitales incrementen eficientemente la producción. 
almacenamiento y transporte de materias primas y bienes energéticos y en la creación de una nueva infraestructura física para integrar estos sectores regionalmente; empero, con un énfasis hacia afuera y hacia los mercados de commodities internacionales. Se busca la reducción de la pobreza sin disminuir los mecanismos de explotación social ni de la transferencia del excedente regional hacia el Norte geopolítico.

Se ignora la existencia de problemas estructurales, bien sea en la esfera productiva (necesidades de complementariedad productiva regional, etc.), bien en la financiera (dependencia hacia un sistema internacional inestable, etc.). Se plantea básicamente la existencia de tres problemas financieros en la región a ser superados por un nuevo banco de desarrollo regional: 1) los elevados costos financieros impuestos a los países más pobres; 2) la baja capacidad de atracción del ahorro intra y extrarregional a la inversión productiva; y 3) la dificultad de disponer recursos para inversiones de más larga maduración.

Por ejemplo, en el reciente trabajo de la profesora Stephany Griffith-Jones ${ }^{6}$ (Griffith-Jones, Griffith-Jones y Hertova, 2007), se analiza el papel de los bancos de desarrollo regionales y subregionales a la luz de la crisis del actual sistema financiero internacional. Ahí se plantea que es deseable la creación de nuevas instituciones como el Banco del Sur, cuando sus objetivos sean "proporcionar bienes públicos regionales que actualmente son insuficientes, como infraestructura regional, y para ayudar a superar nuevos desafíos en el sector productivo representados por los grandes cambios estructurales [acelerada urbanización y problemática ambiental] de la economía mundial" (Griffith-Jones et al., 2007: 32). Así, para el caso específico de Sudamérica, se evidencia que

el Mercosur no tiene un banco de desarrollo subregional para ayudar a financiar la infraestructura de integración productiva y los préstamos -con algún mecanismo concesional-para los países y regiones pobres. Existen nuevas necesidades productivas y medioambientales. Y el desafío de reducir la pobreza, especialmente por medio de la generación de empleos, continúa siendo una cuestión urgente en la región. Por lo tanto, la probable creación del Banco del Sur puede proveer recursos adicionales valiosos para satisfacer las necesidades de la región. Sus préstamos deberían enfocarse especialmente en las áreas donde las instituciones existentes han sido menos activas. (Griffith-Jones et al., 2007: 33, cursivas del autor).

6 Stephany Griffith-Jones es profesora de la universidad de Columbia, EEUU, y directora ejecutiva de la Initiative for Policy Dialogue (IPD), institución fundada por Joseph Stiglitz en 2000 para "ayudar" a los países en desarrollo en su búsqueda de alternativas de políticas económicas. La autora es especialista en flujos de capitales y mercados emergentes, y reconocida por sus críticas a la inestabilidad de los mercados de capitales, así como por sus propuestas de reformas al sistema financiero internacional. 
Finalmente, el trabajo pone énfasis en que "creando nuevas instituciones o expandiendo las existentes - desde que los países en desarrollo sean los miembros exclusivos o principales- se tendrá la ventaja de incrementar sus voces en la asignación de los recursos (...)" (Griffith-Jones et al., 2007: 34, cursivas mías).

Otra característica de esta perspectiva es que el Banco del Sur no tendría diferencias en su estructura organizativa ni en sus objetivos en relación con las instituciones financieras multilaterales ya existentes. Como ejemplo, el economista Luis Becerra (miembro de Economistas de Izquierda-Argentina), en respuesta a un cuestionario elaborado por el Observatorio Internacional de la Deuda (OID) a principios de 2007 sobre el Banco del Sur (Becerra, 2007), expone:

la característica distintiva del Banco del Sur debe ser que los estados fuertes no tendrán poder de veto (EEUU, por ejemplo), como en el caso del Banco Mundial o el BID, aunque para su funcionamiento deberá aplicar reglas similares a las de esos organismos. Además, se supone que los condicionamientos no serán de carácter político. El rasgo distintivo respecto de la banca comercial es que el Banco del Sur (al igual que el BID o el Banco Mundial) no tiene por objetivo el lucro, sino el fomento del desarrollo. Para ello tiene que tener una estructura de costos fijos pequeña (es decir la mínima burocracia posible), que no es el caso del BID y BIRF (Becerra, 2007: 1).

Se ha puesto gran énfasis en la función del Banco del Sur como fuente de recursos para los proyectos de infraestructura de integración productiva (básicamente la "cartera" de la Iniciativa para la Integración de la Infraestructura Regional Suramericana, IIRSA). Griffith-Jones et al. (2007) argumentan ampliamente que una de las principales diferencias entre la operación de Bancos de Desarrollo Multilaterales (Banco Mundial) y Bancos de Desarrollo Regionales y Subregionales es que los últimos deben tener mayor atención al soporte financiero a la "infraestructura regional, por ejemplo, para la Iniciativa para la Integración de la Infraestructura Regional Sudamericana" (Griffith-Jones et al., 2007: 3). Además, añaden estos autores,

la creciente importancia de la integración comercial y los flujos de comercio regionales hacen que la provisión de bienes públicos complementarios regionales -especialmente infraestructura regional- sea muy necesaria. Dadas las importantes imperfecciones de los mercados internacionales de capital privado, especialmente en la provisión de fondeo de largo plazo - tal cual es requerido por la infraestructura-, Bancos de Desarrollo Regionales y Subregionales deben de tener un papel siempre creciente (2007: 6).

O sea, se cree que ¡el Banco del Sur es necesario porque el sistema financiero internacional no funciona como debería funcionar! 
También en el tema del énfasis en la infraestructura de integración productiva se halla la respuesta a la siguiente pregunta formulada por el OID: “¿Cuáles tendrían que ser sus políticas, condiciones y prioridades para el otorgamiento de créditos/ garantías [del Banco del Sur]?"; al respecto, el profesor Franklin Serrano, del Instituto de Economía de la Universidade Federal de Río de Janeiro, dice que la política “debe ser la de financiar inversión pública tanto de integración física de la América del Sur cuanto de largo alcance social (agua, drenaje, electrificación rural, etc.)" (Serrano, 2007: 2).

Sudamérica tiene grandes necesidades de construcción de infraestructura, ya sea de comunicaciones, servicios bancarios, financieros y a empresas, pero principalmente la infraestructura que permita una integración y complementación productiva que comprende los sectores de energía, transporte y almacenamiento, conforme explican Griffith-Jones et al. (2007: 12-18) y Ocampo (2006: 26). Sin embargo, detrás de la construcción de infraestructura de integración actual hay intereses muy poderosos: su prioridad es el transporte en rutas de exportación extrarregional, del que se derivan elevadas ganancias para los sectores exportadores de commodities en este periodo de "anomalía histórica", que consiste en la vigente "bonanza externa" que se considera persiste en la región desde principios de la década de 2000 (CEPAL, 2008b: 144). También se pueden comprender las causas de esta bonanza externa como consecuencia de una situación coyuntural y volátil (CEPAL, 2008c) de elevados precios de las commodities provocada por el acelerado crecimiento asiático, que "se transmitió positivamente por la vía comercial y financiera a la región de América Latina y el Caribe" (CEPAL, 2008b: 147).

De todas formas, establecer como prioridad del Banco del Sur el financiamiento de una estrategia de largo plazo de desarrollo regional orientada hacia afuera puede significar una restricción aún mayor para la estructura productiva, en función de una estrategia supuestamente nacional, pero que tal vez esté peligrosamente sesgada por el excesivo poder político de los empresarios exportadores de materias primas (productos de madera, aluminio, soya, maíz y carnes, derivados de hidrocarburos, minerales, acero, etc.) de la región.

En julio de 2008, la Secretaría General de la Comunidad Andina de Naciones (SGCAN) lanzó el número 2 de la Revista de la integración (SGCAN, 2008), dedicado a apoyar la construcción de la integración sudamericana y, especialmente, la constitución de la Unión de Naciones Suramericanas (Unasur). En este número, igualmente alineado con la idea de que los mercados de capitales solamente necesitan más recursos para apoyar la construcción de infraestructura física, Pablo Solón (2008: 12-18), al analizar el componente de la integración financiera referido en el tratado de la 
Unasur (institución de la cual deriva el Banco del Sur), destaca que

\begin{abstract}
durante el último año y medio han venido trabajando seis grupos de trabajo en el marco de Unasur para definir políticas y acciones a nivel de: 1) integración financiera, 2) infraestructura, 3) energía, 4) políticas sociales, 5) educación, y 6) mecanismos de solución de controversias en materia de inversiones. Muchas iniciativas han sido identificadas y ahora el desafío es su concreción e implementación. De entre todas ellas es de destacar aquellas que hacen a la integración financiera y que pueden ir involucrando a todos los estados miembro: • El desarrollo de un sistema multilateral voluntario de pagos en moneda local que permita ir sustituyendo el dólar en nuestras transacciones interregionales; $\bullet$ El fortalecimiento de mecanismos regionales para la estabilización de la balanza de pagos con el objetivo de hacer frente a desequilibrios comerciales transitorios y/ o ataques especulativos contra una moneda local; • Un plan para avanzar en la integración de los mercados financieros y de capitales de la región; • Un mecanismo y un proceso de coordinación de los fondos financieros regionales para proyectos de desarrollo y de integración en infraestructura (2008: 18).
\end{abstract}

Sin embargo, el Banco del Sur en ese momento no era un proyecto consensual del ámbito de la Unasur (Solón, 2008: 27), por ello, en este número de la revista no se desarrolla más profundamente el debate específico en cuanto a las necesidades de una nueva institucionalidad financiera para la región.

Además, el Acta Fundacional del Banco del Sur, de diciembre de 2007, ya había asimilado perfectamente el argumento académico de la necesidad de desarrollo de los mercados de capitales regionales, cuando en su texto considera que "las estructuras económicas y financieras de América del Sur evidencian limitaciones en el desarrollo de los mercados financieros" (Acta Fundacional del Banco del Sur, 2007: 1).

\title{
Banco del Sur: cambio estructural
}

Por otro lado, Fabrina Furtado (2007a), de la Rede Brasil sobre Instituições Financeiras Multilaterais, agrega al debate sobre la creación del Banco del Sur elementos críticos de extrema importancia. La Rede Brasil tiene una trayectoria de enfrentamiento de los problemas ambientales y sociales generados por la construcción de las obras de infraestructura de integración física en la región amazónica (Carvalho, 2002; Furtado, 2006; Garzon, 2007; Gomes, 2006; Novoa, 2007). En sus trabajos se han logrado identificar dos importantes relaciones:

1) Por un lado, la visión económica dominante promueve la idea de una relación de dependencia directa entre la superación del subdesarrollo y la inversión en obras de infraestructura de interconexión comercial, promoviendo la ilusión de que en Sudamérica el desarrollo puede ser alcanzado sencillamente por medio 
de la adopción de políticas que eleven el financiamiento de la infraestructura para la exploración, transporte, transformación y exportación de la base material natural hacia el exterior; $y$

2) también han identificado que los mecanismos de financiamiento de la construcción de esa infraestructura son elementos de creación de lazos de dependencia financiera y política que completan "el círculo vicioso del endeudamiento financiero, social y ecológico" de Sudamérica (Furtado, 2007).

Una importante conclusión derivada del desenredo de estas contradicciones es que "el proyecto del Banco del Sur no será una alternativa a las Instituciones Financieras Multilaterales mientras se oriente a incrementar los recursos hacia el financiamiento de la infraestructura física para la exportación", y más específicamente, de la "cartera" de proyectos de infraestructura física de integración organizada por el BID bajo la Iniciativa para la Integración de la Infraestructura Regional Sudamericana?

Según las aportaciones de estos autores, el Banco del Sur estaría siguiendo exactamente las mismas directrices de financiamiento de la explotación de las materias primas sudamericanas establecida originalmente por el Banco Mundial, conforme explica también el capítulo 2 del libro de Éric Toussaint:

En el curso de los primeros diecisiete años de existencia, los proyectos apoyados por el Banco Mundial consistían en mejorar la infraestructura de comunicación y la producción de electricidad. El dinero prestado a los PED debía ser gastado, sobre todo, en los países industrializados. Los proyectos apoyados debían mejorar la capacidad de exportar del Sur hacia el Norte, a fin de satisfacer las necesidades de éste y enriquecer a un puñado de sociedades multinacionales de los sectores concernidos. Durante este periodo, los proyectos relativos a la enseñanza, la salud, el acceso al agua potable y el saneamiento de las aguas residuales eran inexistentes.

Desde el principio, las misiones del Banco tendían, esencialmente, a aumentar su capacidad de influencia sobre las decisiones tomadas por las autoridades de un país dado en un sentido favorable a las grandes potencias accionistas y a sus empresas (Toussaint, 2007) . $^{8}$

Así, en segundo lugar está la perspectiva que sostiene que una estrategia creíble de desarrollo debe priorizar una mirada estructural de más largo plazo que sea compati-

7 "IIRSA es una política de reforma estructural basada en la necesidad de extracción de recursos y creación de una base física para que las corporaciones transnacionales expandan sus actividades y controlen los territorios y recursos estratégicos, como las fuentes de energía, agua y biodiversidad, completando así el círculo vicioso del endeudamiento financiero, social y ecológico" (Furtado, 2007: 8).

8 El extracto del capítulo 2, "Los comienzos del Banco Mundial: 1946-1962" del libro Banco mundial: El golpe de Estado permanente, de Éric Toussaint (2007), también está disponible en línea y traducido al español: www.cadtm.org/spip.php?article2123. 
ble con una integración institucional financiera que 1) supere los límites monetarios, y en especial, crediticios regionales; 2) apoye la diversificación productiva general con la elevación del valor agregado y la diversidad de los productos exportables (reducción relativa de la exportación de productos primarios); 3) favorezca la formación de bases tecnológicas endógenas; 4) disminuya la dependencia política, económica y cultural externa; y 5) mitigue los mecanismos de reproducción de la pobreza, de desigualdad en la distribución del ingreso y de fragmentación social. Por cierto, parece improbable que una solución para los problemas del subdesarrollo basada en esos cinco puntos derive de un proceso automático impulsado por los intereses de un sector exportador de materias primas o dé las "señales" determinadas exógenamente por los mercados consumidores internacionales.

Por lo que el impulso constitutivo de una nueva institución para el desarrollo regional que pretenda superar los problemas del subdesarrollo con una mirada estructural sin duda debe proporcionar más que el incremento del ahorro regional, especialmente superando la mera construcción de infraestructura de integración física para el sector exportador de materias primas.

En la búsqueda de estos objetivos, las prioridades para el Banco del Sur pueden ser distintas a las involucradas en la reducción de costos para la exportación de los productos primarios, como bien responde al cuestionario del OID Gladys Hernández (2007), del Centro de Investigación de la Economía Mundial de Cuba:

El comercio y la inversión no deben ser fines en sí mismos, sino instrumentos para alcanzar un desarrollo justo y sustentable, ya que la verdadera integración latinoamericana y caribeña sólo podrá alcanzarse a través de una estrategia integral de desarrollo que abarque mucho más que la intención de ampliar los mercados externos o estimular el comercio. En este sentido, se requiere una efectiva participación del Estado como regulador y coordinador de la actividad económica y financiera.

El Banco del Sur debe contar con un plan estratégico de posibles objetivos a financiar, que comprendan inversiones de interés mutuo en iguales condiciones que las realizadas por entidades nacionales. Estas inversiones pueden adoptar la forma de empresas mixtas, producciones cooperadas, proyectos de administración conjunta y otras modalidades de asociación que decidan establecer para garantizar la más beneficiosa complementación productiva sobre bases de racionalidad, aprovechamiento de ventajas existentes en una y otra parte, ahorro de recursos, ampliación del empleo útil, acceso a mercados u otra consideración sustentada en una verdadera solidaridad que potencie las fuerzas de ambas partes.

Entre los proyectos a considerar puede incluirse el financiamiento de paquetes tecnológicos integrales desarrollados por los países interesados, en áreas de interés común, que serán facilitados para su utilización y aprovechamiento, basados en principios de mutuo beneficio. Entre estos proyectos pudieran incluirse programas para eliminar el analfabetismo en terceros países, utilizando métodos de aplicación masiva de probada y rápida eficacia, puestos en práctica exitosamente en la República Bolivariana de Venezuela. Igualmente 
pudieran incluirse proyectos vinculados a programas de salud (Hernández, 2007: 3-4).

Por lo tanto, parece ser acertado recalcar la necesidad de que el Banco del Sur busque en el tema de la integración regional, "una estrategia de diversificación y complementariedad productiva que reduzca la dependencia externa", sin dejar de aprovechar con cautela la coyuntura externa favorable para los productos primarios.

Ahora bien, éstas son las ideas que se derivan de la crítica estructural. Se traza una nueva estructura financiera regional que trata de ir más allá de la realización de una complementariedad de recursos.

El proceso de transformación sistémica propuesto por esta perspectiva más crítica no ignora la necesidad de elevar la cantidad de recursos disponibles a bajos costos para inversiones productivas con largos plazos de maduración. Sin embargo, se le da la misma importancia a la necesidad de dar solución al problema estructural del endeudamiento externo público y la condición estructural de dependencia de los flujos de capitales hacia la región.

Esta perspectiva propone un Banco del Sur que colabore para que el flujo de inversiones sea estable y adecuado a la demanda de recursos para el financiamiento de inversiones productivas para el desarrollo, independientemente del buen humor de los mercados financieros.

También se propone un banco de desarrollo que contribuya a romper con los mecanismos de la dependencia financiera en la que los capitales excedentes del proceso de acumulación regional sudamericanos migran inexorablemente hacia los principales centros financieros del exterior. Es decir, se desea disminuir la subordinación de los intereses capitalistas nacionales respecto de los poseedores de capitales "cosmopolitas" y, en consecuencia, esta postura crítica plantea la mitigación de las medidas neoliberales que garantizan bajo cualesquiera condiciones las ganancias y los intereses del capital financiero.

A mediados de 2006, el politólogo belga y presidente del Comité para la Anulación de la Deuda del Tercer Mundo (CADTM), Éric Toussaint, preocupado por la cuestión estructural financiera, explicó su propuesta para que el Banco del Sur ayude a:

romper la dependencia de los países periféricos del mercado financiero internacional, canalizar la capacidad propia de ahorro, detener la fuga de capitales, canalizar los recursos centrales a las prioridades de un desarrollo económico y social independiente, cambiar las prioridades de inversión, etc. Se trata de un banco público alternativo al BID y al Banco Mundial. [...] El Banco del Sur no puede estar disociado del problema de la deuda. Hay que evitar que su actividad sirva para mantener la gestión de la deuda pública en beneficio del capital financiero (Toussaint, 2006). 
Romper la dependencia sudamericana del mercado financiero internacional significa más que elevar o tornar más eficiente la capacidad de ahorro regional, aunque esta dimensión sea importante en las actuales condiciones de los flujos financieros de capitales regionales hacia los mercados estadounidenses y europeos. En este sentido, una institucionalidad financiera realmente renovada tiene que ser capaz de elevar la inversión productiva independientemente de las condiciones de creación de ahorro regional -mecanismo que suele actuar procíclicamente y con elevados costos en mercados de capitales abiertos y desregulados. Conforme lo anterior, además de engrosar la esfera financiera -no bancaria-, sobre el Banco del Sur se depositan las esperanzas de que pueda surgir una institucionalidad financiera regional capaz de extender el acceso al crédito a los diversos sectores sociales, ampliar la capacidad crediticia, reducir los costos financieros, bloquear los mecanismos de transmisión de crisis financieras e incrementar los plazos del sector bancario sudamericano.

En esta materia, se destaca la proposición elocuente de septiembre de 2007 de José Félix Rivas Alvarado, entonces director del Banco Central Venezolano y actualmente ministro de Finanzas de ese país, para que el Banco del Sur cierre las venas abiertas de América Latina. Según su análisis,

uno de los mecanismos del círculo vicioso de la dependencia es la dinámica entre los flujos financieros de ahorro e inversión. Se trata de revertir la tendencia del transvase de recursos financieros de la región hacia los principales centros financieros. Por tanto, se intenta cerrar esta vena abierta de América Latina, para aprovechar productivamente estos recursos. Se ha sostenido desde hace mucho tiempo, el argumento de que uno de los problemas para financiar el desarrollo de la región era la "insuficiencia de ahorro", resultando en una trágica paradoja el hecho de que se acumulen en los mercados financieros internacionales importantes recursos provenientes de este Sur. Se trata de demostrar que es posible convertir los recursos financieros que puede generar la región aprovechándolos endógenamente para consolidar nuestras estructuras productivas y superar las llamadas brechas sociales. Sin embargo, esta legítima intención se enfrentará a la lógica del predominio del capital financiero especulativo sobre el capital productivo.

La estrategia del Banco del Sur tiene que estar orientada hacia el logro de mayores grados de autonomía que permita combinar el desarrollo con la independencia. La independencia financiera y económica hace viable la independencia política. Éste es el camino para terminar con el tutelaje y la intervención de los organismos multilaterales en nuestras políticas económicas (Rivas Alvarado, 2007).

Empero, es en la perspectiva de la necesidad de reducir la injerencia del BM, el FMI y sus políticas recesivas sobre la economía sudamericana donde, aparentemente, se apoya la defensa académica para el progreso de las negociaciones y la concretización del Banco del Sur. Esta idea se basa en que el apoyo financiero promocionado por estas instituciones y por los mercados privados de capitales es de carácter rece- 
sivo para la región. Como consecuencia, estos académicos diseñan un Banco del Sur como un "mecanismo de gestión y administración diferente y alternativo al que ha caracterizado al FMI y el BM, cuyos préstamos siempre han estado sometidos a condicionantes que van desde la presión para la privatización de bienes públicos, hasta el extremo control en la política económica en general y de la fiscal en particular; además de ejercer presión para la liberalización de las actividades económicas al capital privado nacional y extranjero, así como la ordenación de la política social" (Cabrera, 2008: 13-14).

\section{El actual silencio académico}

A pesar de la urgencia del avance del debate anterior, parece sintomático que algunas fuentes de pensamiento académico importantes se hayan callado durante todo el proceso de creación del Banco del Sur, que se ha intensificado por la participación de académicos y organizaciones no gubernamentales desde 2007.

En este sentido, un ejercicio de exploración por noticias, artículos, documentos de trabajo y demás publicaciones de los sitios de internet de la Asociación Latinoamericana de Integración (ALADI), la Comisión Económica para América Latina y el Caribe (CEPAL), el BID y el BM reveló un asombroso silencio y vaciamiento del debate académico. Más bien, sus jefes y voceros "no saben qué decir": justamente eso fue lo que el 14 de abril 2007 contestó Anoop Singh, el entonces responsable del departamento de América Latina del FMI, al ser interrogado sobre el proceso de constitución de un Banco del Sur, durante una reunión del BID con ministros de Economía de los países de la región (González y Brooks, 2007; IMF, 2007).

Una investigación con base en los documentos y publicaciones disponibles en el sitio de internet de la ALADI revela solamente el conocimiento del proceso de constitución del Banco del Sur, en el Informe del secretario general sobre la evolución del proceso de integración regional durante el año 2007 (SGALADI, 2008: 59), pero sin mayor profundidad o aportaciones al debate. De la misma forma, ni el portal oficial del Mercosur ni el portal de la Comunidad Andina de Naciones ${ }^{9}$ han apoyado publicaciones que contengan contribuciones sustanciales al debate académico sobre el proceso de constitución del Banco del Sur o respecto de la necesidad de cambios sobre la institucionalidad financiera regional.

9 Véanse estudios detallados sobre la constitución de la Unasur así como una pequeña descripción del proceso de creación del Banco del Sur en la Revista de la integración (SGCAN, 2008). 
Una revisión detallada de los últimos seis números de la Revista $C E P A L^{10}$ muestra diversos artículos sobre la crisis financiera actual, la inserción externa de la región sudamericana, la pobreza, el desarrollo regional, la integración regional, muchas referencias a la Unión Europea, al BID, al BM, al FMI, pero ninguna mención a la Unión de Naciones Suramericanas ni al proceso de integración regional sudamericana o latinoamericana, y menos en relación con el Banco del Sur o sobre el Fondo Monetario del Sur.

En el libro editado por la CEPAL, La transformación productiva 20 años después. Viejos problemas, nuevas oportunidades (CEPAL, 2008a), se hace un profundo estudio sobre las "opciones para los países de la región" (CEPAL, 2008a: 54-58) ante las necesidades de integración y coordinación económicas en materia de favorecimiento de las exportaciones que, según el texto, "facilitaría enormemente la tarea al brindar escala, complementariedades y acumulación de aprendizajes" (CEPAL, 2008a: 14). Pero en ningún momento menciona el debate concerniente al Banco del Sur, tampoco las necesidades de creación de una nueva arquitectura financiera regional ni las necesidades de complementariedad de los recursos para la inversión de integración en la región.

De igual modo, el libro de Luis Machinea y Serra (2007), editado por la CEPAL, que trata largamente la cuestión de la búsqueda de la reducción de la pobreza, el mayor bienestar de las personas y el desarrollo latinoamericano, tampoco hace mención al proceso de integración regional sudamericana o latinoamericana, a la Unión de Naciones Suramericanas, el Banco del Sur ni el Fondo Monetario del Sur.

Ya el reciente libro Estudio económico de América Latina y el Caribe, 2007-2008. Política macroeconómica y volatilidad (CEPAL, 2008b) hace un estudio más detallado y actualizado sobre la condición externa latinoamericana reciente, y el cambio de coyuntura internacional e inserción latinoamericana. En el estudio se proponen alternativas de políticas contracíclicas para los países de la región dirigidas a reducir la volatilidad del crecimiento, identificando elementos importantes de la "bonanza externa" (CEPAL, 2008b: 144) y explicando el creciente superávit externo y fiscal, condiciones importantes para la creación de un nuevo banco de desarrollo regional en Sudamérica, pero sin mencionar los planes de integración de la institucionalidad financiera que se están proponiendo para la región, y sin referencias al proyecto es-

10 Véanse los ejemplares de la Revista CEPAL, núm. 97, abril de 2009: www.cepal.org/publicaciones/xml/1/35861/RVE97completo.pdf; núm. 96, diciembre de 2008: www.cepal.org/publicaciones/xml/6/34916/RVE96Completa.pdf; núm. 95, agosto de 2008: www.eclac.org/publicaciones/xml/0/33760/RVE95completa.pdf; núm. 94, abril de 2008: www.eclac.org/publicaciones/ xml/3/32733/Revista94Completa.pdf; núm. 93, diciembre de 2007: www.eclac.org/publicaciones/ xml/2/31962/RVE93completo.pdf; y núm. 92, agosto de 2007: www.eclac.org/publicaciones/ xml/5/29595/RVE92Completo.pdf. 
pecífico del Banco del Sur.

Tampoco el libro de septiembre de 2008, La volatilidad de los precios internacionales y los retos de política económica en América Latina y el Caribe (CEPAL, 2008c) trata del Banco del Sur, aunque hace un análisis sobre la volatilidad de los elementos que sustentan la actual bonanza externa sudamericana y la inercia de las políticas económicas delante del riesgo de reversión en la situación externa, que sirve como argumento en defensa de un imperioso cambio en la estructura financiera regional.

Menos afortunada resultó la búsqueda de análisis del tema del Banco del Sur entre la inmensa producción académica del FMI y el BID, aunque muchos informes, revistas y otros trabajos publicados por el Instituto para la Integración de América Latina y el Caribe (Intal) -institución del BID- hagan referencia a la necesidad de incrementar las inversiones en infraestructura física en la región ${ }^{11}$. La principal referencia está en el Informe Mercosur núm. 12 (2006-2007) (INTAL, 2007), que sintetiza, aunque sin analizar, la trayectoria hasta octubre de 2007 de la constitución del Banco, enfatizando su papel conductor de la liquidez regional "para lograr financiamiento de largo plazo para proyectos de infraestructura" (INTAL, 2007: 58).

Que el Banco Mundial y el Fondo Monetario Internacional no mencionen ni de paso las necesidades de desarrollo de propuestas como la del Banco del Sur, no resulta novedoso ni contradice las políticas e intereses de estas instituciones. Sin embargo, sí es preocupante el silencio inoportuno y aparentemente deliberado de instituciones que tradicionalmente han promovido el debate académico de carácter regional e integrador, como es el caso de la CEPAL.

Tal vez se pueda inferir que la escasa discusión académica sobre la problemática enfrentada, los objetivos y la estructura técnica del Banco del Sur tenga como causa y consecuencia la incorporación de gran parte de la forma e ideología cómplice con la estabilidad de la todavía vigente estructura financiera internacional en las instituciones de fomento al debate científico. O quizá se deba a que la academia está más ocupada en la construcción de modelos teóricos para la comprensión de las causas y los efectos de la vigente crisis que en la necesidad de crear proyectos para salir de ella.

Pese al hecho de que muchos otros autores estén trabajando en pro de la construcción de un banco de desarrollo regional coherente con la ruptura del patrón de expansión del sistema financiero internacional, hasta este momento el proyecto ${ }^{12} \mathrm{del}$ Banco del Sur avanza sin intención de romper con cualquier elemento del patrón de

11 Las publicaciones del INTAL están disponibles en: www.iadb.org/intal/detalle_articulo_publicacion. asp?idioma $=\mathrm{esp} \&$ aid $=809 \& \mathrm{cid}=234$.

12 Cfr. el contenido del Acta Fundacional del Banco del Sur (2007) y Resultados del Taller Técnico Banco del Sur (2008).

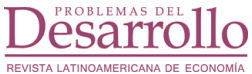

Vol. 41, núm. 160, enero-marzo / 2010 
desarrollo del sistema capitalista existente, ni con propósitos de constituir una renovada institucionalidad financiera regional.

El discurso de la nueva institucionalidad financiera regional seguirá vacío de contenido mientras no se incorporen en los planes políticos elementos concretos de esta nueva arquitectura regional. De hecho, basar la nueva estructura financiera en un Banco del Sur completamente compatible con la modernización financiera regional en términos neoliberales, que utilice las reservas de divisas existentes para la expansión y mayor liberalización de los mercados de capitales regionales y para la creación de nuevas formas de valorización del capital financiero -aunque sea para la inversión en proyectos con el objetivo del desarrollo regional-, sólo puede reproducir, en escala regional, la mundialización financiera.

Muchos trabajos ${ }^{13}$ ya han probado que los objetivos últimos del Banco Mundial -el principal modelo de banco de desarrollo del planeta- son mantener la condición de subdesarrollo latinoamericano y beneficiar económicamente a los países centrales de este sistema. Y esas metas se han alcanzado no sólo por medio de la influencia estadounidense o europea sobre esta institución, sino en especial por su capacidad de reproducir regionalmente la ideología capitalista en su fase neoliberal, o sea, la estructura privada, abierta y liberalizada de los mercados de capitales de los países centrales. ¿Qué nueva arquitectura financiera regional se puede constituir en la reproducción de este modelo de banco de desarrollo?

No se puede ocultar que en el asunto falta cierta dosis de creatividad y osadía, o quizá el tema revele una imposibilidad estructural de que se pueda crear una propuesta alternativa para un banco de desarrollo regional sudamericano ${ }^{14}$. Y esta falta de creatividad empieza por la ausencia de un fuerte debate sobre el tema precisamente en el momento en que los representantes de los gobiernos sudamericanos están decidiendo sobre la creación de esta institución. Debate en donde incluso autores dedicados a la crítica de la desregulación e hipertrofia del sistema financiero internacional como François Chesnais y Michel Aglietta se han callado sin que -hasta el momento en que se produce este trabajo- hayan hecho públicos análisis sobre temas de importancia para el Banco del Sur.

Sin duda, gran parte del esfuerzo de los autores que trabajan el tema del Banco del Sur es promocionar el proyecto para que se establezca rápidamente en la región.

13 Véase, por ejemplo, el trabajo de Éric Toussaint, World Bank: a never ending coup d'État: the hidden agenda of Washington Consensus (Toussaint, 2007).

14 Un claro ejemplo al respecto es que una de las primeras versiones discutidas del borrador del convenio constitutivo del Banco del Sur de octubre de 2007 es una reproducción adaptada del Convenio Constitutivo del Banco Interamericano de Desarrollo. 
De forma que se defienden una u otra propuestas para esta institución, pero con una comprensible cautela para evitar que se critique en demasía los elementos negativos para cada visión del proyecto. Sin embargo, que el Banco del Sur sea parte de la nueva arquitectura financiera regional en Sudamérica será un hecho en la medida en que se efectúe su constitución. No obstante, que esta nueva arquitectura financiera regional sea una alternativa real al sistema financiero internacional es el tema del debate que se ha ignorado y al que debería dársele prioridad sobre la mera promoción no crítica del Banco.

\section{Bibliografía}

Acta Fundacional del Banco del Sur, Acta, Buenos Aires, 2007, en: http://www.integracionsur.com/sudamerica/ActaFundacionBancoSur2007.pdf

González Amador, Roberto y David Brooks, Banco del Sur acapara atención de la reunión del FMI y el BM, Liège, Bélgica, Comité para la Anulación de la Deuda del Tercer Mundo, 18 de abril de 2007: http:// www.cadtm.org/Banco-del-Sur-acaparaatencion-de

Becerra, Luis, Respuesta de Luis Becerra, Argentina, al cuestionario de OID sobre el Banco del Sur, Documento electrónico, 2007, en: http://www.oid-ido.org/IMG/pdf/ BANSURR1.pdf

Cabrera, S., Renovadas crisis, renovadas alternativas para América Latina: El Banco del Sur, Ponencia presentada en el VIII Seminario de Economía Fiscal y Financiera, México, IIEc, UNAM, 1, 2 y 3 de abril de 2008.

Carvalho, Guilherme, IFMs e a integração da infra-estrutura na América do Sul e seu rebatimento sobre a Amazônia: o caso do Avança Brasil, Documento electrónico, 2002, en: www.rbrasil.org.br/content, $0,0,178,0,0 . h t m l$

CEPAL (Comisión Económica para América Latina y el Caribe), La transformación productiva 20 años después. Viejos problemas, nuevas oportunidades, Santiago de Chile, CEPAL, mayo, 2008a, en: http://www.eclac. org/publicaciones/xml/7/33277/2008-117SES.32-Latransformacion-WEB_OK.pdf

, Estudio económico de América Latina y el Caribe, 2007-2008, Santiago de Chile, CEPAL, agosto, 2008b, en: http://www. eclac.org/cgi-bin/getProd.asp?xml=/publicaciones/xml/9/33869/P33869.xml\&xsl=/ de/tpl/p9f.xsl\&base=/tpl/top-bottom.xsl La volatilidad de los precios internacionales y los retos de política económica en América Latina y el Caribe, Santiago de Chile, CEPAL, septiembre, 2008c, en: http://www.eclac.cl/noticias/paginas/7/33937/2008-621_volatilidad.pdf

Crespilho, Fabiano, El proyecto del Banco del Sur, Tesis de Maestría en Economía, México, Facultad de Economía, UNAM, 2009.

, "Banco del Sur y medio ambiente", Ola financiera, núm. 5, México, IIEC-Facultad de Economía, UNAM, enero-abril de 2010, en: www.olafinanciera.unam.mx/ new_web/pdfs/05/Crespilho.pdf

Declaración de Quito, Quito, Ecuador, 3 de mayo de 2007, en: www.choike.org/documentos/declaracion_quito.pdf

Furtado, F., As Instituições Financeiras Multilaterais, a dívida financeira, ecológica e social e a integração regional. $O$ caso da IIRSA, Documento electrónico, diciembre de 2006, en: www.rbrasil.org.br/content, $0,0,1901,0,0 . \mathrm{html}$

, Banco del Sur, una perspectiva de integración desde los pueblos, Documento presentado durante el taller del Jubileo Sur, Américas y Rede Brasil sobre Instituições Financeiras Multilaterais, en diciembre de 2007, 2007a, en: www.rbrasil.org.br / file 1919.pdf

Garzon, L. F. N., Usinas no Madeira, Documento electrónico, 2007, en: www.rbrasil.org.br/ content, $0,0,2014,0,0 . h$ tml

Gomes, H., Empresas estatais brasileiras como plataformas para a IIRSA. A política externa do Brasil e as propostas alternativas de integração latino-americana, Documento electrónico, 2006, en: www.rbrasil.org.br/ content, $0,0,1518,0,0 . h t m l$

Vol. 41, núm. 160, enero-marzo / 2010 
Griffith-Jones, Stephany, David Griffith-Jones y Dagmar Hertova, Enhancing the role of regional development banks; the time is now, Documento preparado para la reunión del Grupo Intergubernamental de los Veinticuatro (G-24), 2007, en: www.g24.org/ sgj0907.pdf

Hernández, Gladys, Respuesta de Gladys Hernández, Cuba, al cuestionario de OID sobre el Banco del Sur, Documento electrónico, 2007, en: www.oid-ido.org/IMG/pdf/bansurr2.pdf

IMF (International Monetary Fund), Transcript of a Press Briefing on the Regional Economic Outlook: Western Hemisphere Department, Washington DC, International Monetary Fund, 13 de abril de 2007, en: www.imf.org/external/np/tr/2007/ tr070413a.htm

INTAL (Instituto para la Integración de América Latina y el Caribe), Informe Mercosur, segundo semestre 2006-primer semestre 2007, núm. 12, Buenos Aires, BID-INTAL, noviembre de 2007, en: www.iadb.org/intal/ aplicaciones/uploads/publicaciones/e_Informe_MERCOSUR_12.pdf

Machinea, José Luis y Narcís Serra (eds.), Visiones del desarrollo en América Latina, Santiago de Chile, CEPAL, junio de 2007, en: www.eclac.org/publicaciones/xml/0/29200/ CIDOB-CEPALVisiones.pdf

Novoa, L. F., Madeira: o leilão do que não tem preço, Documento electrónico, 2007, en: www.rbrasil.org.br/content, 0,0,2245,0,0. html

Ocampo, José Antonio, "La cooperación financiera regional: experiencias y desafíos", en J. A. Ocampo (comp.), Cooperación financiera regional, Santiago de Chile, CEPAL, septiembre de 2006, en: www.cepal.org/ publicaciones/xml/5/27495/lcg2319e.pdf

Rivas Alvarado, José Félix, El Banco del Sur: concepción sin pecado original, Documento electrónico, CADTM, 2007, en: www. cadtm.org/spip.php?article2847

Serrano, Franklin, Respuesta de Franklin Serrano, Argentina, al cuestionario de OID sobre el Banco del Sur, Documento electrónico, 2007, en: www.oid-ido.org/IMG/ pdf/BANSURR3.pdf
SGALADI (Secretaría General de la Asociación Latinoamericana de Integración), Informe del secretario general sobre la evolución del proceso de integración regional durante el año 2007, Montevideo, SGALADI, 2008, en: www.aladi.org/nsfaladi/estudios.nsf/d ecd25d818b0d76c032567da0062fec1/39f 2505e2691d0a90325740f006b4edc/\$FIL E/2136.pdf

SGCAN (Secretaría General de la Comunidad Andina de Naciones), Revista de la integración, núm. 2, Lima, Secretaría General de la Comunidad Andina, julio de 2008, en: www.comunidadandina.org/public/revista_unasur.pdf

Solón, P., "Reflexiones a mano alzada sobre el Tratado de UNASUR" Revista de la integración, núm. 2, Lima, Secretaría General de la Comunidad Andina, julio de 2008, pp. 12-18, en: www.comunidadandina.org/public/revista_unasur.pdf

Taller Técnico Banco del Sur, Resultados del taller técnico Banco del Sur, Documento elaborado como conclusión del Taller Técnico sobre el Banco del Sur, realizado en Quito, 23-27 de junio de 2008, en: www. choike.org/documentos/resultados_taller_ banco_del_sur.pdf

Toussaint, Éric, Banco del Sur, marco internacional y alternativas, Documento preliminar preparado para el seminario del Observatorio Internacional de la Deuda, Caracas, 22-24 de septiembre de 2006, Liège, Bélgica, CADTM, 2006, en: www.cadtm.org/ article.php3?id_article $=2001$

The World Bank: a never ending coup d'État: the hidden agenda of Washington Consensus, Karnataka, la India, Vikas Adhyayan Kendra, 2007.

, Banco del Sur y nueva crisis internacional, Quito, CADTM, 2008, en: www. vientosur.info/documentos/Banco $\% 20$ del\%20sur\%2026Abril08.pdf

Valenzuela, Lídice, "Banco del Sur versus crisis financiera", CubAhora, 3 de junio de 2009, en: www.cubahora.cu/index. php?tpl=principal/ver-noticias/ver-not ptda.tpl.html\&newsid_obj_id=1032088 


\section{INSTITUTO DE INVESTIGACIONES ECONÓMICAS-UNAM}

\section{Seminarios}

2010

\author{
9-11 XIII Seminario \\ Economía, Ciencia y Tecnología \\ Una visión panorámica
}

을

13-15 IV Seminario

Situación y Perspectivas

del Sector Eléctrico en México

El concepto servicio público de electricidad y los servicios de interés general

21-24 XX Seminario Economía Urbana y Regional

Programa sujeto a cambios
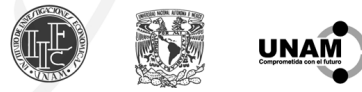

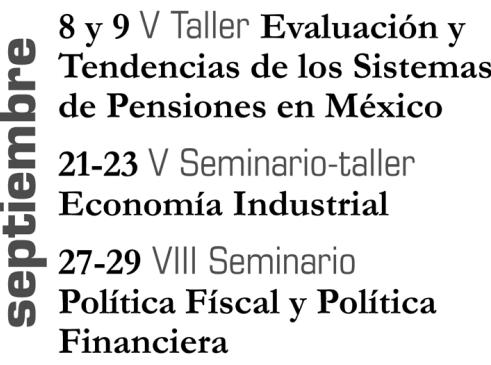

4-7 XXX Seminario Economía Agrícola

d 19 y 20 V Seminario

Internacional de Economía Mundial

26-28 || Seminario

Concepciones contemporáneas de la pobreza

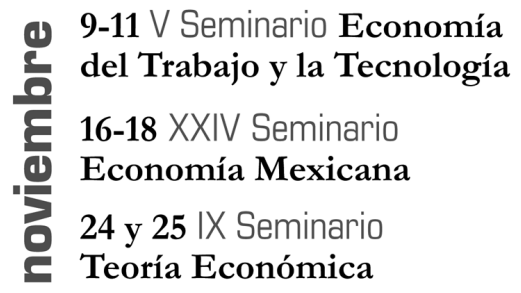

Mayores informes:

Secretaría Académica, Departamento de Difusión Académica y Promoción Institucional del llEc Circuito Mario de la Cueva s/n, Ciudad de la Investigación en Humanidades, Ciudad Universitaria, México D.F. Tels. 56230093 y $56230099 /$ difuiiec@servidor.unam.mx/www.iiec.unam.mx 